\title{
Using Learning Communities to Successfully Navigate through the Stages of Graduate Education at a Small Medical School
}

\author{
Karen Russell Randall ${ }^{1}$, Ph.D., Danita Eatman², Ph.D., Ashley Kennedy Mitchell ${ }^{3}$, MSPH, Meryl \\ $\mathrm{McNeal}^{4}$, Ph.D. \\ ${ }^{1}$ Department of Pharmacology and Toxicology and Department of Microbiology, Biochemistry, and Immunology, \\ Morehouse School of Medicine, Atlanta, United States \\ ${ }^{2}$ Department of Medical Education and Department of Pharmacology and Toxicology, Morehouse School of \\ Medicine, Atlanta, United States \\ ${ }^{3}$ Quality Enhancement Plan, Morehouse School of Medicine, Atlanta, United States \\ ${ }^{4}$ Department of Medical Education and Department of Community Health \& Preventive Medicine and Quality \\ Enhancement Plan, Morehouse School of Medicine, Atlanta, United States \\ Email: mmcneal@msm.edu \\ All authors contributed equally to this manuscript.
}

\begin{abstract}
New students are often challenged with the transition from undergraduate to graduate school. To enhance student progress and success, Learning Communities (LCs) were established at Morehouse School of Medicine (MSM) in 2012. The LC's purpose is to form a supportive learning environment that encourages student connectivity to faculty and peers and promotes graduate school completion. Students were divided into LCs by degree programs and then further divided into stages. Year 1 sessions focused on topics related to students' transition from undergraduate to graduate school. Sessions were faculty-facilitated and student led, with 2 peer mentors. Students completed assessments at individual sessions, mid-year, and end of year. Data from Academic Years 2012-2015 indicated $100 \%$ of $\mathrm{PhD} 1 \mathrm{LC}$ respondents and $82 \%$ of MSBR $1 \mathrm{LC}$ respondents report participating in Learning Communities was an overall good/outstanding experience. Based on preliminary data, more students are meeting degree requirements on the designated timeline.
\end{abstract}

Keywords: Underrepresented minority students, mentoring, learning communities, training biomedical students, learning environment

\section{Introduction}

Participation of under-represented minorities (URMs) in science, technology, engineering, and math (STEM) remains low. The National Center for Education Statistics reported that during the academic year of 2011-2012, less than 4,000 Ph.D. degrees were awarded to URMs out of the over 41,000 Ph.D. degrees conferred in United States institutions in STEM (National Center for Education Statistics [NCES], 2013). This indicates that only approximately $10 \%$ of the terminal degrees conferred during that academic year were to URMs. It is worth noting that about 2.5 times as many URMs were graduating from college in STEM majors during this same time (Tull, Rutledge, Carter, \& Warnick, 2012). Based on these findings, there appears to be a disconnect between the number of URMs graduating with STEM undergraduate degrees to those completing doctoral degrees in the same disciplines. Two possible problems related to URMs obtaining graduate degrees are: 1) applying and/or being admitted to graduate school, and 2) successfully completing graduate school. This paper will address the second issue of URMs successfully completing their graduate education. Our students are highly motivated; however, many students enter programs lacking some of the skills needed for successful completion of graduate school. We are addressing this problem at Morehouse School of Medicine (MSM) through the development of a novel learning community mentoring program designed to support students' academic experiences and their learning environment. Our learning communities address topics such as time to degree, finding an advisor, choosing a lab, meeting milestones, and exam taking skills. This article describes the promising Graduate Education in Biomedical Sciences (GEBS) Learning Community program at MSM. 
The National Science Foundation (NSF) recognized a need to improve retention and graduation rates of URMs in STEM disciplines at the graduate level and has supported this effort (Tull et al., 2012). Due to NSF's initiatives, several institutions have developed programs to address the needs of URMs. For example, the University of Maryland (UM) developed a program aimed at providing professional development activities that would facilitate retention and successful graduation of a diverse pool of Ph.Ds. in all STEM fields (Tull et al., 2012). To address retention and graduation issues, MSM's Quality Enhancement Plan (QEP) developed learning communities for graduate students in the biomedical sciences. Our QEP, Mentoring Students at Morehouse, is part of our accreditation requirement for the Southern Association of Colleges and Schools- Commission on Colleges (SACSCOC). Our goals for the QEP are to: 1) establish learning communities for students at MSM, and 2) train faculty learning community mentors. Therefore, to enhance student progress and success, GEBS Learning Communities (LCs) were established at MSM in 2012 with the purpose of sustaining students' academic success through the key stages of graduate training.

At MSM, GEBS students are placed in LCs based on their specific degree programs: Ph.D., Master of Science in Biomedical Research (MSBR), Master of Science in Medical Science (MSMS), and Master of Science in Clinical Research (MSCR). They are further divided based on their stage in their respective programs. The topics discussed were initially determined by faculty, the school's clinical psychologist, program deans, and current literature. Topics were also suggested by the students themselves on their evaluations.

Learning community topics are organized to meet student needs in their stage of development. Based on our experiences, students that have already earned one graduate degree find the transition to graduate school smoother than recent undergraduates. One of the major challenges for the recent undergraduates lies with understanding what is expected of them as graduate students as they transition from undergraduate to graduate school. They are also challenged with getting past the shock that grades are often determined differently in graduate courses than in undergraduate courses. This transition is therefore one of the early topics that is discussed. During the first semester of graduate school at MSM, students often become very stressed and have a difficult time managing their work load and maintaining a balanced life. Since work and personal life can impact students both positively and negatively (Carlson, Kacmar, Wayne, \& Grzywacz, 2006; Grawitch, Barber, \& Justice, 2010), students are often encouraged to discuss balance and related life issues openly and honestly in learning community sessions.

Graduate students in other graduate institutions have reported that graduate school can be a lonely place that impedes students' success (Hawlery, 2003; Ali \& Kohun, 2006). The graduate school experience can be overwhelming at times and ultimately impede the performance of an otherwise outstanding student. Thus, if students are to be successful in graduate school, it is imperative that they quickly understand the learning environment and culture in which they are immersed. Connecting faculty, students and peer mentors in the 6-8 learning community sessions during the first year of graduate school offers an opportunity to help them stay on course and feel supported.

The primary goal of this article is to report the findings from our first vear MSBR and Ph.D. programs over the initial 3 years (2012-2015), and demonstrate that learning communities developed in graduate programs can improve student outcomes and behaviors, such as managing stress and preventing burnout, and time management among others. In this document, we will describe the components and impact of graduate LCs on student skillsets and competencies at Morehouse School of Medicine.

\section{$2 \quad$ Methodology}

In the GEBS program, students were divided into learning communities by degree programs and years. The learning communities being reported in this article are:

1. MSBR Year 1 Learning Community

2. Ph.D. Year 1 Learning Community

QEP staff organized ongoing planning meetings with faculty to identify learning community topics, dates, mentor assignments, develop discussion guides and identify evaluation concerns. Year 1 sessions focused on topics related to students' transition from undergraduate to graduate school. Sessions were 
faculty-facilitated and student led, with 2 near-peer mentors. Four areas were identified to assess learning community success. Those areas were:

1. Transition into graduate school

2. Faculty/student and peer to peer relationships

3. Improved skillsets and competencies

4. Overall learning community experience

\subsection{Student Evaluations}

Students completed short assessments on individual learning community sessions, a mid-year assessment, and an end of the year assessment, as well as participated in an end of year focus group. Self-report surveys on individual sessions asked students if they liked specific sessions, if they were informative, or helpful; and their thoughts on whether participation in learning communities helped them to feel connected. In the interim and end of year surveys, students self-reported on the improvement of skills addressed in learning communities, overall learning community satisfaction, and learning community environment. Learning community assessments on individual sessions were completed on paper by students immediately after each session. Students completed the interim and end of year reports via a Survey Monkey link.

\subsection{Data Analysis}

We conducted a content analysis on all the student assessments to identify trends in phrases used by students to describe learning community strengths and areas of improvement. Quantitative questions from the mid-year and end of year were calculated using SPSS and Survey Monkey.

\section{$3 \quad$ Results}

\subsection{Graduate School Transitions}

For Academic Years 2012-2015, $61 \%$ of Ph.D. 1 Learning Community survey respondents strongly agreed or agreed that learning communities helped them to adjust to graduate school transitions (Figure 1A). MSBR 1 Learning Community agreement was higher at $88 \%$ of student respondents (Figure 1B).
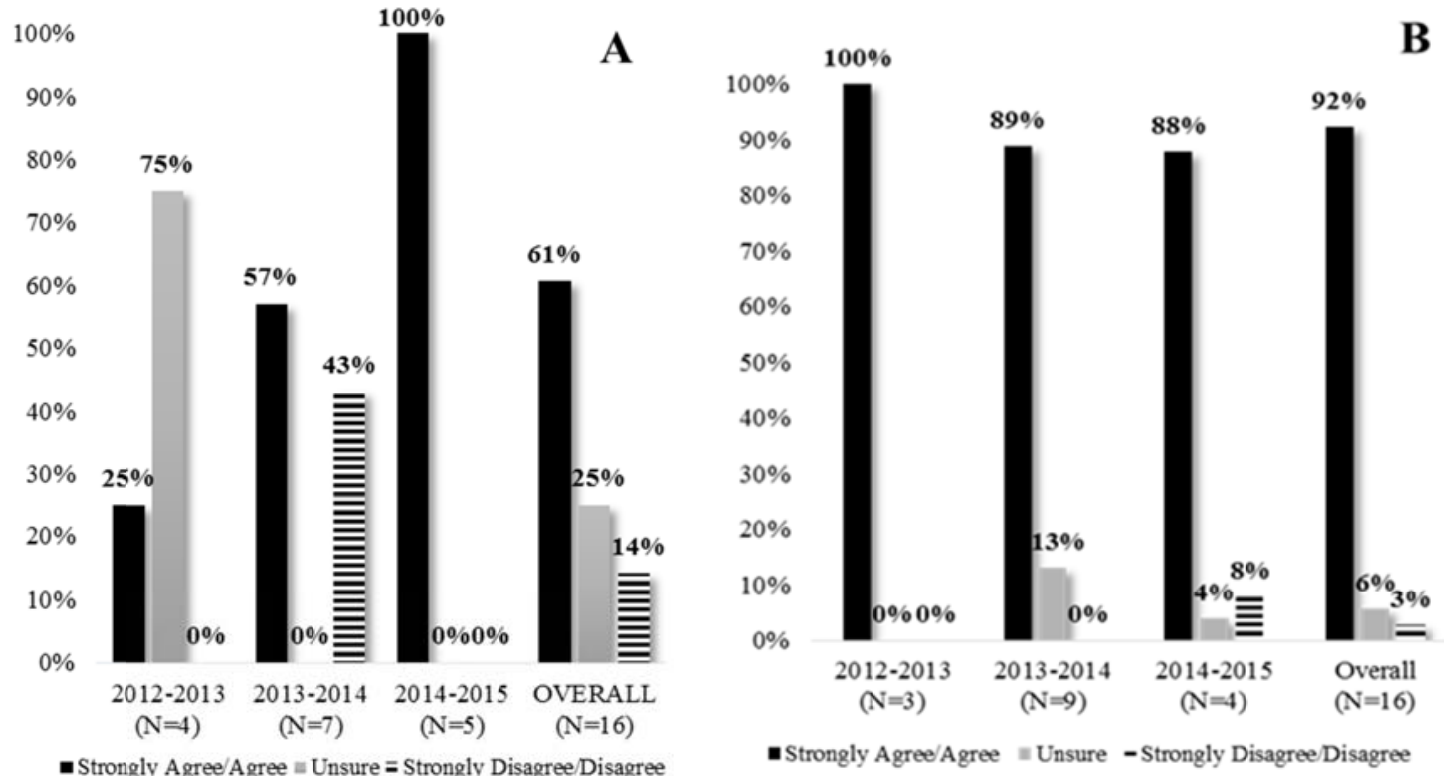

Figures 1A \& 1B. Figures 1A (PHD Year 1) and 1B (MSBR Year 1) learning communities AY 2012-2015: participating in my learning community has helped me adjust to graduate school transitions. 


\subsection{Improved Skillsets and Competencies}

For Academic Years 2012-2015, the percent of overall Ph.D. 1 LC student respondents that agreed was highest when asked if leaning communities helped to better manage stress and prevent burn out (80\%) and enhance time management skills (80\%) (Figure 2A). The percent of overall MSBR 1 LC student respondents that agreed was highest when asked if learning communities helped to enhance their understanding of the examination process (100\%) (Figure 2B). Ph.D. 1 and MSBR 1 LC respondents had the lowest overall percentage agreement for learning communities helping to enhance their time management skills (49\% and 54\%, respectively). Scores were lower for most categories in year 2012-2013, the implementation year for learning communities in the MSM GEBS programs.

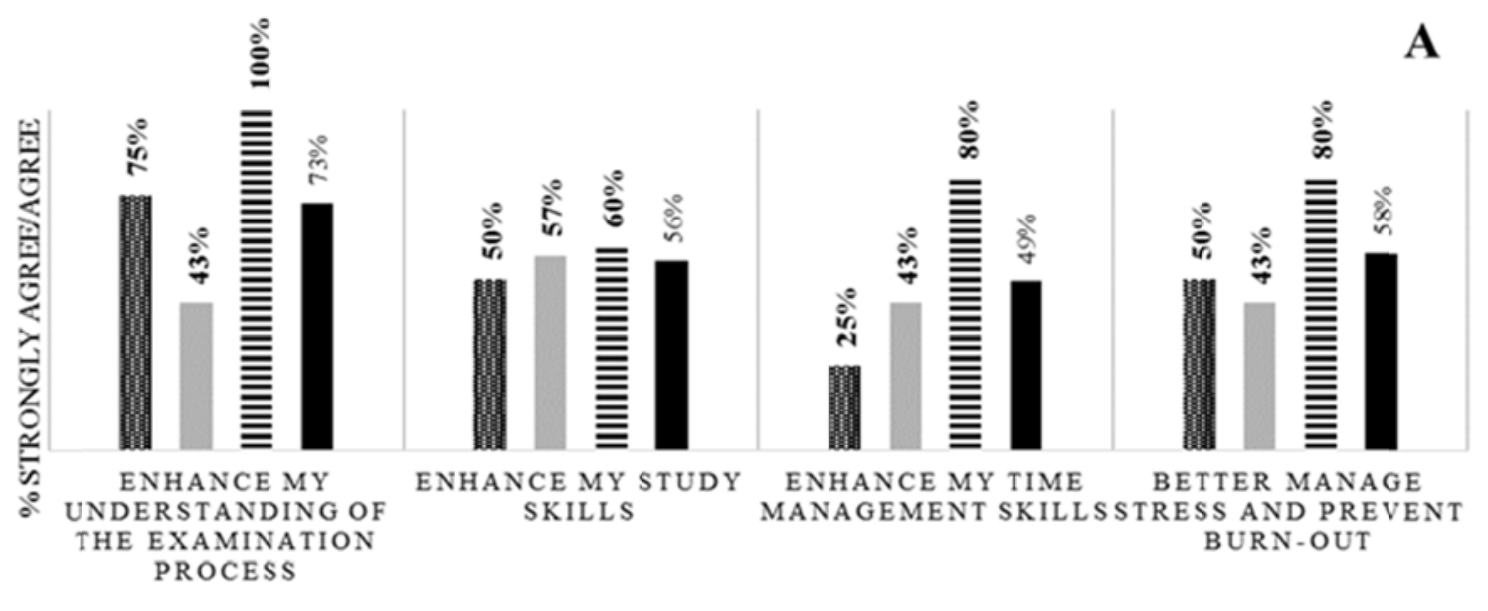

జ2012-2013 $(\mathrm{N}=4)=2013-2014(\mathrm{~N}=7)=2014-2015(\mathrm{~N}=5)$ - Overall $(\mathrm{N}=16)$

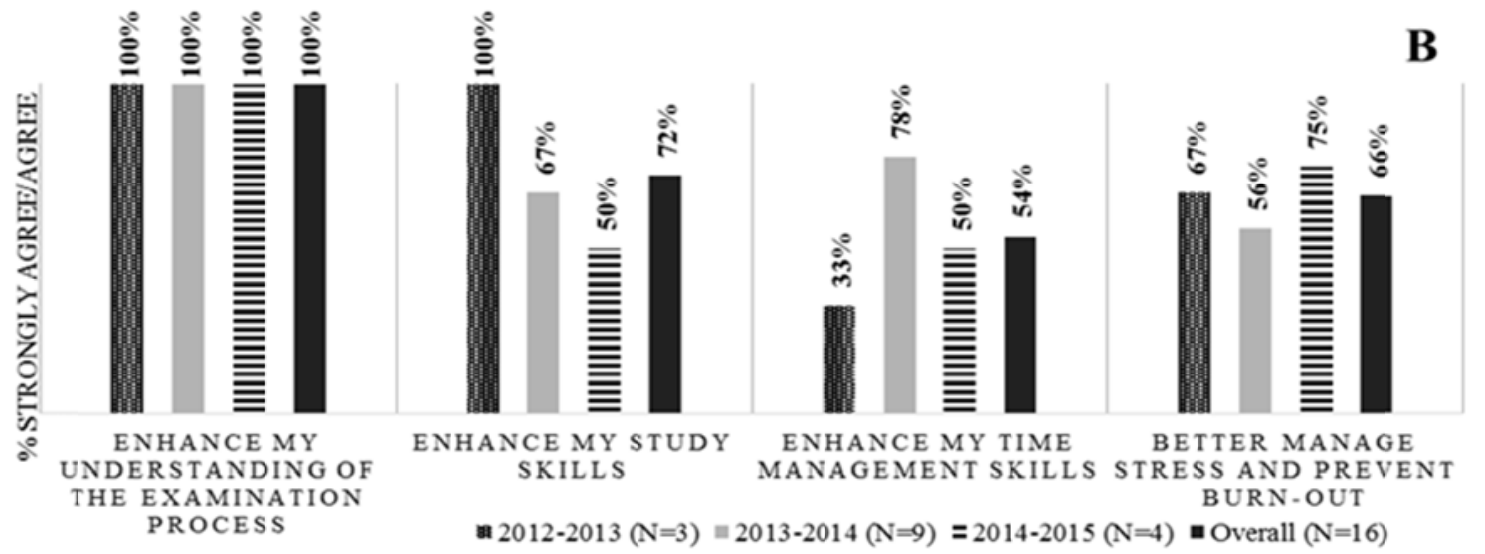

Figures 2A \& 2B. Figures 2A (PHD Year 1) and 2B (MSBR Year 1) learning communities AY 2012-2015: participating in my learning community has helped me to.

\subsection{Learning Community Experience}

$100 \%$ of Ph.D. 1 LC student respondents and $82 \%$ of MSBR 1 LC student respondents report participating in MSM GEBS Learning Communities was an overall good or outstanding experience (Figures 3A \& 3B). Ph.D. 1 LC responses were consistent each year while there were variations in the experiences for MSBR 1 students in Academic years 2012-2013 and 2013-2014. 
A

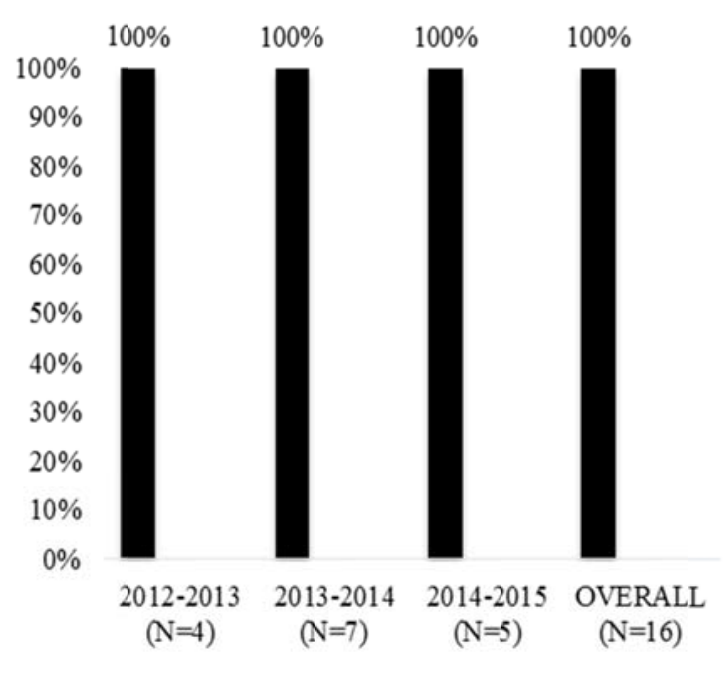

- Outstanding/Good = Average "Mediocre (Fair)/Poor
B

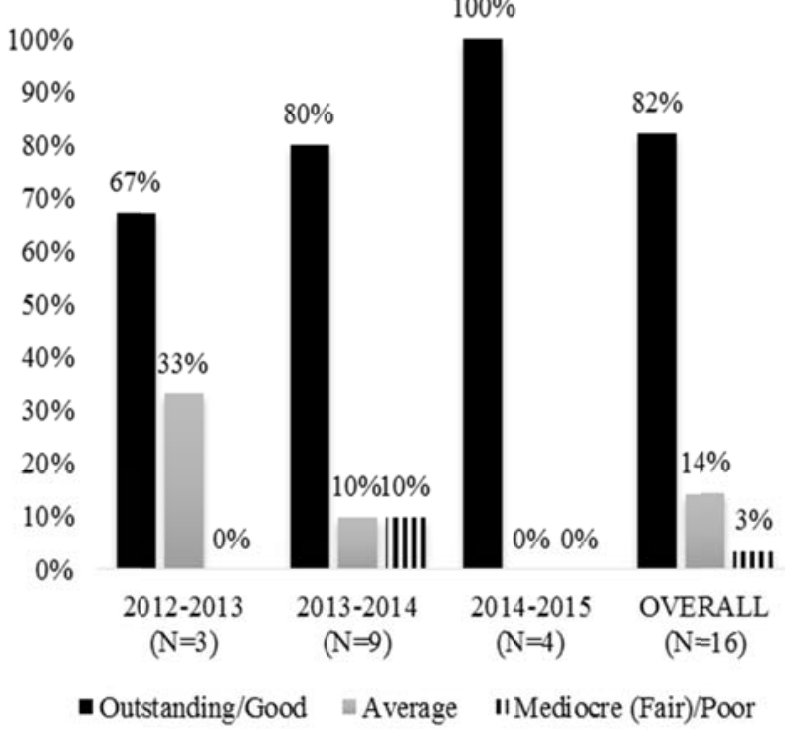

Figure 3A \& 3B. Figures 3A (PHD Year 1) and 3B (MSBR Year 1) learning communities AY 2012-2015: overall experience

In Figure 4, GEBS Learning Communities student respondents for all program years were asked to give three words that describe learning communities in Academic Year 2014-2015. Based on their responses, a word cloud was generated. For this word cloud, size was related to number of mentions. Helpful was the most used word. Other commonly used words were insightful, interactive, necessary, supportive, engaging, interesting, and fun.

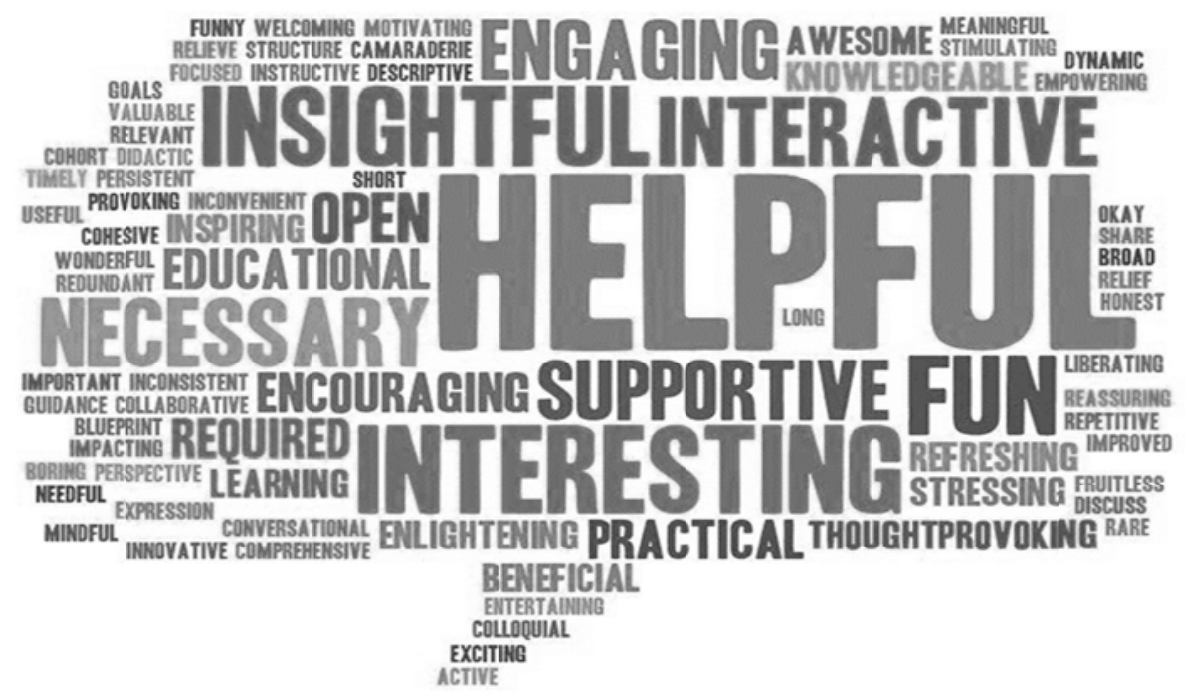

Figure 4. Student word cloud: words that describe learning communities $(\mathbb{N}=247)$ 


\section{Discussion}

MSM is dedicated to increasing the diversity of the health professional and scientific workforce, and since the inception of the Ph.D. program in 1992, has successfully graduated more than sixty underrepresented minority scientists who entered careers in various biomedical science arenas. As with other graduate programs, when students matriculate they are often challenged with the transition from undergraduate to graduate school. This is a major transition process for students and they are often overwhelmed with the workload and with trying to maintain a balanced life (Ogilvie and Hernández Jr., 2013). Also, many graduate students are often challenged to move successfully through the different stages of the graduate program, whether the Master of Science (M.S.) or the Ph.D., and therefore to complete their graduate work in a timely manner. Based on the data presented, the inclusion of LCs in the graduate curriculum helped students with the transition from undergraduate to graduate school. We report success with this program based on students' responses of outstanding overall experiences in LCs.

The first year students in both the Master of Science in Biomedical Research (MSBR) and the Ph.D. programs strongly agreed that participation in learning communities helped them to adjust to the MSM environment (Figure 1A). The MSBR students found more value in these sessions than did the Ph.D. students. Although it is not evident why this is consistently the case, it is possible that since the students in the MSBR program are expected to complete their degree requirements within a shorter time period, (2 years), they appreciate assistance with assimilation much more that the Ph.D. students do. This matter will be addressed in future research. Also, it should be noted that a few of the matriculating Ph.D. students have already earned a Master's degree and were of the opinion that they already knew what graduate school was all about. By the end of the first semester, however, students already having Master's degrees often express that the experience at MSM was very different from that of their previous academic institution. Another school of thought is that Ph.D. students are of the opinion that they know what they are doing and so need less assistance than the other graduate students. Our data could also be skewed by the fact that our numbers are low and a negative/different opinion by one (1) or two (2) students has a major impact on the outcome.

The skill sets that were evaluated for this study included: enhanced understanding of the examination process at MSM, enhanced study skills and time management skills, and school/life balance. These skill sets are often a challenge for our graduate students. It is interesting to note that the Ph.D. students in the 2014 entering class were consistently in strong agreement that being involved in learning communities improved their skill sets in all areas evaluated (Figure 2A). All of these students entered the graduate program at MSM directly from undergraduate programs, and the entire graduate experience was new to them. Based on self-report, the learning communities as structured, appear to be helping Ph.D. and MSBR students improve the skill sets needed to successfully complete their first year of the graduate program.

Based on the data, the first year graduate students in the biomedical sciences at MSM have an outstanding experience in learning communities (Figures 3A \& 3B). They are very engaged in the sessions, and particularly enjoy sessions in which they hear the personal experiences of the more advanced students. The year 1 students find the sessions helpful, interesting and insightful (see word cloud). Some of the student testimonials include:

1. "Learning community mentors are already doing an excellent job facilitating personal and professional growth." -MSBR Student

2. "The thing I like most about learning community is having a safe space to discuss issues/obstacles that we as students encounter as we matriculate at MSM." -MSBR Student

3. "I get to learn different types of skill including dealing with stress, community work, goals, how to pick a lab that is right for you, and time management." -MSBR Student

4. "Great mentorship and professionalism! (My mentor) is very supportive and provides a welcoming attitude that is easy to relate with." -Ph.D. Student

5. "Our mentor actually cared that we had our learning community. You could go to her office. They actually really do care." -Ph.D. Student

6. "I liked the ability to be able to talk among my peers about learning and growing through this educational process". - Ph.D. Student 
Although the majority of the comments from students were very positive, we did have some students providing concerns about the need for consistent scheduling and the time required to attend sessions. Some students state that learning communities take away from their study time. Learning community faculty have adjusted learning community schedules to accommodate these concerns.

The learning communities in the graduate education curriculum at MSM were established to provide an open and supportive environment where students with a common goal can share their opinions and ideas. Students receive support from faculty and near-peer mentors who help them to resolve problems and discuss issues relevant to their success in graduate school. A study by Zhao and Kuh (2004) demonstrated that participation of college students in some form of learning community, was positively related to student success, including self-reported gains since starting college. A similar program established for graduate students at Ohio State University indicated that the students developed a sense of community, and very importantly, there was a reduction in the attrition rate of minority students. Although our numbers are small, our data support these findings. Our results support the idea that the incorporation of learning communities in the graduate school experience at MSM had similar success, and that students benefitted from the mentoring.

Our data provide evidence that learning communities are educationally effective for our students. Our data also support Zhao and Kuh's (2004) findings that "learning communities are associated with enhanced integration of academic and social experience, gains in multiple areas of skills, competence, and knowledge, and overall satisfaction with graduate school experience." The first year students at MSM improved in various areas of skill competence and knowledge as they continue in their graduate research program. This learning community program is still in the early stages and needs additional assessment to determine students' sense of community as well as outcomes. The current findings, however, indicate that learning communities are having a positive impact on graduate students' performance at Morehouse School of Medicine.

\subsection{Limitations}

This study has several limitations of which the most significant is that the graduate program at MSM is still quite young (inception 1992). The implementation of the GEBS learning communities is also relatively new with its establishment in academic year 2012-2013. Although there was a fledgling start in the 2011 academic year, there was no defined structure to it until the following year. As a result of this, there are not enough years for accumulation of data. Another very important limitation is our sample size. The number of students in the GEBS program is small, therefore, one or two students can have a major impact on the overall outcome, and can skew the data in one direction or another. Future research will require more years of data with larger sample sizes. The small sample size also makes it difficult to determine which of the competencies or environmental factors being reported actually contributed the most to the students' overall satisfaction with LCs. Further investigation is necessary in order to determine these associations.

\subsection{Implications and Future Research}

While curricular learning communities are common in undergraduate institutions, they are less so in graduate education, but are becoming a growing trend. The implementation of such a program in the graduate curriculum at MSM is thought to be an innovative approach to graduate education and is believed to add value to the graduate experience. This is shown in our data, which indicates that our students find their LCs to be helpful, supportive and interesting. It is our expectation that participation in learning communities will influence student learning, and personal and professional development. One of the goals of the GEBS LCs is to help students meet their curricular milestones and complete their training in a timely manner. It is difficult at this early stage since implementation to determine if this is being accomplished. It is expected however, that this goal will be accomplished and data providing this information will be in a future manuscript.

Minority student retention is an ongoing problem in various graduate institutions (Tull et al., 2012; Kosoko-Lasaki, Sonnino, \& Voytko, 2006) and there are various strategies in place to address this problem. It has been suggested that learning communities be used as a general strategy to retain graduate students (Kraska, 2008), and we believe that curricular learning communities for graduate 
students will provide a general model for larger institutions to enhance the learning environment and improve the retention of their minority students. The learning communities will help to create an environment in which underrepresented minority students will feel a part of their learning environment and not feel isolated. This is an important tool that should include activities focused on professional and social development. LCs will provide an opportunity to keep students more engaged and will have the added value of providing an environment in which students can directly interact with faculty and peer mentors. These students will be working together towards a common goal and will be more likely to complete their graduate education.

Acknowledgements. Dr. Meryl McNeal and Ashley Kennedy Mitchell had full access to the data in the study and take responsibility for the data's integrity and the accuracy of the data analysis. We would like to acknowledge the following faculty who have assisted with the GEBS learning communities program: Martha Elks, M.D., Ph.D., Douglas Paulsen, Ph.D., Shawn Garrison, Ph.D. and Todd White, Ph.D.

\section{References}

1. Ali, A., \& Kohun, F. (2006). Dealing with isolation feelings in IS doctoral programs. International Journal of Doctoral Studies, 1(1), 21-33.

2. Carlson, D. S., Kacmar, M. K., Wayne, J. H., \& Grzywacz, J. G. (2006). Measuring the positive side of the work-family interface: Development and validation of a work-family enrichment scale. Journal of Vocational Behavior, 68(1), 131-164.

3. Grawitch M. J., Barber L. K., Justice L. (2010). Rethinking the work-life interface: it's not about balance, it's about resource allocation. Appl. Psychol. Heal. Well-Being 2 127-159.

4. Hawley, P. (2010). Being bright is not enough: The unwritten rules of doctoral study. Charles C Thomas Publisher.

5. Kosoko-Lasaki, O., Sonnino, R. E., \& Voytko, M. L. (2006). Mentoring for women and underrepresented minority faculty and students: experience at two institutions of higher education. Journal of the National Medical Association, 98(9), 1449

6. Kraska, M. (2008). Retention of Graduate Students Through Learning Communities, Journal of Industrial Teacher Education, 45(2), 54-70.

7. Ogilvie, C. A., \& Hernández Jr., I. (2013). Graduate Student Learning Communities at Iowa State University. Graduate College Reports. Paper 2. http://lib.dr.iastate.edu/grad_reports/2

8. Tull, R. G., Rutledge, J. C., Carter, F. D., \& Warnick, J. E. (2012). PROMISE: Maryland's Alliance for Graduate Education and the Professoriate enhances recruitment and retention of underrepresented minority graduate students. Academic Medicine, 87(11), 1562-1569.

9. Zhao, C. M., \& Kuh, G. D. (2004). Adding value: Learning communities and student engagement. Research in Higher Education, 45(2), 115-138. 